\title{
Design and Realization of Residential Property Management Information System Based on Browser/Server Mode
}

\author{
Mingze $\mathrm{Ma}^{1}$ \\ ${ }^{1}$ Affiliation not available
}

February 17, 2021

\begin{abstract}
In response to the needs of Chinese community residents for property management, this article designed and developed a residential property management information system based on the B/S model. The system development adopts the browser/server (B/S) architecture, Java as the development language, the framework adopts Spring MVC mode, the MySQL database is used, the source code and database interaction process uses the Mybatis framework, and the front-end display uses the VUE.js framework to realize the residential property. Manage the data reporting and statistics of each link.Functional modules include:owner information, real estate information, engineering equipment, personnel management, lease management. The system has passed the functional test, ,It has been in trial operation for one year in multiple residential communities. The results show:the system has the characteristics of simple operation, stable operation, strong scalability, etc., which can assist property managers in scientific, convenient and efficient community property management, improve the informatization and modernization of community property management, enhance the experience of community owners, and improve the satisfaction of community owners degree.
\end{abstract}

Design and Realization of Residential Property Management Information System Based on Browser/Server Mode

\section{Mingze Ma}

School of software(Shandong University), Jina 250101, Shandong, China

Email:mmzmmz181@163.com

\section{Summary}

In response to the needs of Chinese community residents for property management, this article designed and developed a residential property management information system based on the B/S model. The system development adopts the browser/server (B/S) architecture, Java as the development language, the framework adopts Spring MVC mode, the MySQL database is used, the source code and database interaction process uses the Mybatis framework, and the front-end display uses the VUE.js framework to realize the residential property. Manage the data reporting and statistics of each link.Functional modules include:owner information, real estate information, engineering equipment, personnel management, lease management.The system has passed the functional test, It has been in trial operation for one year in multiple residential communities. The results show:the system has the characteristics of simple operation, stable operation, strong scalability, etc., which can assist property managers in scientific, convenient and efficient community property management, improve the informatization and modernization of community property management, enhance the experience of community owners, and improve the satisfaction of community owners degree.

\section{KEYWORDS}


Information system,management,browser/server,springMVC,My-

SQL database

\section{1-INTRODUCTION}

China's property management informatization construction began in the 1990s, and after 30 years of development, some achievements have been made.In system design and development, Zeng xiyin combined ASP.NET technology, B/S and C/S architecture to design and implement an Internet-based property management system. ${ }^{1}$ Under the framework of B/S mode, Liu ruoyu analyzed the charge management, equipment and expense management in property management, and designed the property management system under $\mathrm{B} / \mathrm{S}$ mode $^{2}$ In the system development, Wei zhongyi and others designed and implemented the community property management system based on .NET from the aspects of financial charging, complaint management, parking space management, etc. ${ }^{3}$ Sun zhonghua studied the B/S mode of intelligent community property management system from the aspects of community parking lot monitoring, meter reading and charging. ${ }^{4}$ Based on the J2EE platform, An sibo uses Spring and B/S framework to design and implement a WEB-based residential property management system in the system design and development process. ${ }^{5}$ Liu chunli and $\mathrm{Xu}$ chenglin design an ASP.NET-based intelligent community property management system. ${ }^{6}$ Yang jun, Zhang huaqiang and others combined with the needs of property management, analyzed and studied several modules such as property charges, and designed and used SSH to build a residential property management system. ${ }^{7}$ Zhong luo and others analyzed the design plan of the property management system, designed and implemented the property management system based on Struts and JDO. ${ }^{8}$ Chen hui uses Visual Basic and ACCESS tools to study the residential property management system based on VB development. ${ }^{9}$ Based on the SSH architecture, Hu fengjuan uses B/S to design and implement a property management system based on the SSH architecture. ${ }^{10}$ Yao fen analyzes the current status and development trend of property management, and designs the ASP.NET architecture of the property management system. ${ }^{11} \mathrm{Wu}$ linglin uses the B/S architecture and LINQ to SQL technology to study the residential property management system based on LINQ technology. ${ }^{12}$ At the same time, some foreign experts and scholars in property management have also studied,such as Alice christudason analysis suggests the two were selected on the basis that, although they share certain similar characteristics including age, tenure and locational attributes, each employs different systems of property management,data were gathered mainly through interviews with the Property Managers and Chairs of the Management Council. ${ }^{13}$ And as B. klingenberg and R.J. brown analysis suggests, Optimization of residential property management.it expands the existing literature of the agency problem in real estate by providing an optimization model for management of investment properties. ${ }^{14}$

As an important part of informatization, the property management information system has developed rapidly under the impetus of information technology and computer technology.Especially in recent years, the development and application of intelligent property management has become the key to improving the market competitiveness of property companies. However, compared with developed countries, China's property management information system still has some problems. Specifically, they are mainly reflected in:

(1)The information system has a single function and cannot realize the comprehensive service management of the community property;

(2)Part of the information system does not meet the actual needs, the operating efficiency of the system is low, the role is not fully utilized, the data security and data accuracy are not high, and the time for querying, creating and updating pages is too long;

(3)Poor information system compatibility;

(4)The intelligence of the information system is low, and the property management is still point-to-point manual management;

(5)The accumulation of basic data for residential property management is limited, and many business data are still mainly recorded manually. The movement of personnel or the relocation of office locations may 
cause the loss of historical data, and paper materials are difficult to store for a long time.

Therefore, in the future development, how to develop a realistic, low-threshold, and systematic property management information system has become one of the urgent problems to be solved.

Combined with the characteristics of property management, there are not many reports on the community property management information system covering all aspects of property management. this article aims to change the current property management methods and improve the efficiency of property management, by summarizing the informatization needs of the property management process of each community, aiming at the large and medium-sized communities of the "community + community" model, a set of property management information system has been designed and developed using Java technology that is simple, object-oriented, distributed, robust, and safe, organically combine traditional property management with the Internet, manages and displays the elements of community owners, real estate, equipment and facilities, personnel, and leases on the Internet, and realizes the accurate recording, management, query and analysis of the entire process of community property management, statistics, as well as the uploading and issuing of various notices between communities and communities, enables property management personnel to view and report anytime and anywhere, freeing property management personnel from tedious data filling, statistics, summary, uploading, and distributing, so that the property Managers conduct community property management scientifically, conveniently and efficiently, serve the community well, enhance the experience of community owners, and improve the satisfaction of community owners.

\section{2-RESIDENTIA PROPERTY MANAGEMENT INFORMATION SYSTEM DESIGN}

\section{1 - Demand analysis and data collection}

Through the investigation of multiple residentia, it was found that almost all of the communities under investigation did not use the property management system, and still used manual "work" methods to manage the communities. At the same time, a large number of texts, tables and graphics were collected during the survey. Analyzing the received data, it is found that the data is diversified, the format is random, and the filling is random, which involves all aspects of property management. Organize and analyze the collected data, extract data structure and functional requirements, and determine the system development technical framework.

\section{2-Database design}

The property management mode determines the multi-level characteristics of the data in each link of the property management of the community, and the database is designed as an attribute database.The attribute database covers basic information of the community, data related to property management, etc.According to some community data collected in the survey, the attribute data is classified according to the system function settings, and is specifically divided into data such as owners, real estate, engineering equipment, personnel management, and lease management.

\section{3-System development technology architecture}

The Browser/Server(B/S)mode is the most widely used structure in the development of property management information systems. The property management information system developed by the B/S mode is simple, convenient, safe, and stable. When developing the property management information system, the functions of the property management information system are reflected on the server. In actual applications, as long as the relevant hardware and software facilities, such as databases, are installed on the server side, users can access and operate the property management information system through a browser. After logging in to the property management information system through the browser, the user clicks on the corresponding The module can call the database to realize the functional operation of the property management information system. The B/S mode is not restricted by time and location, and users can access and operate the system where there is Internet. The property management information system developed by the B/S model has relatively low cost, short development cycle and high development efficiency. The system has strong scalability, understandability, testability, modifiability, portability, and Reusability, easy maintenance, good 
system compatibility, and users do not need to install special applications on the computer when accessing applications.

The system development adopts the B/S mode (Browser/Server) with a three-tier architecture for system construction. The first layer is customer service. System administrators, property management managers, property management personnel and community owners are authorized The residential property management information system can be accessed and operated through the Internet within the scope of the customer service. The VUE.js framework is used for customer service. It is the bridge between the user and the system. It has the functions of displaying data and receiving user input. Coordinated operation; The second layer is business services, which are undertaken by the Web server of the property information center, responsible for the operation of data services, and provide interactive interfaces for customer services, which have the effect of connecting the previous and the next. The development of business services adopts the Spring MVC framework pattern. Spring MVC separates the roles of controllers, model objects, filters, and handler objects. Through the definition of interfaces and configuration files, the dependencies between classes are completely decoupled; ${ }^{15}$ The third layer is data services. The database server located in the property information center stores all information and data related to property management and provides data or data services for business services. Application deployment supports Windows/Linux server operating systems, source code and The database interaction process uses the Mybatis framework, and the database uses the MySQL database management system. The technical framework of system development is shown in Figure 1.

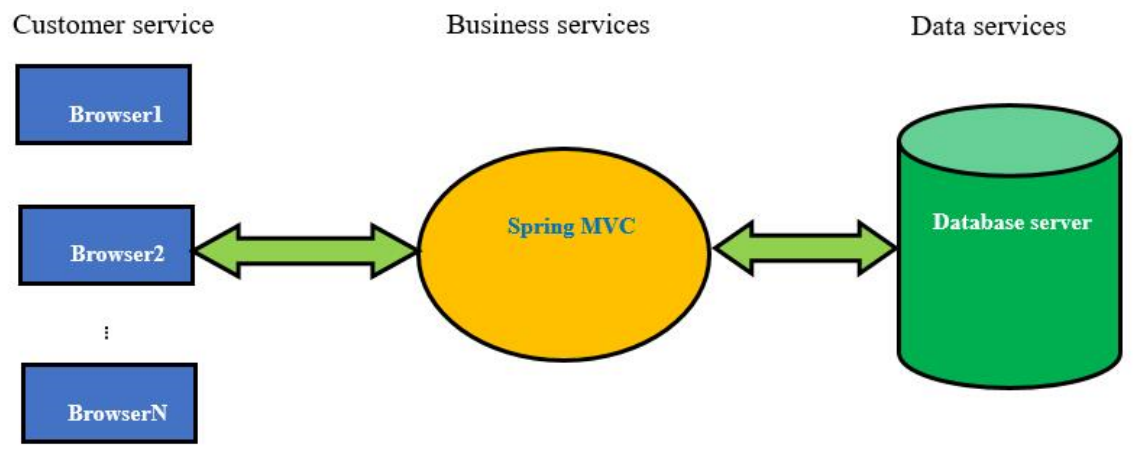

FIGURE 1 System development technology architecture diagram

\section{3-SYSTEM IMPLEMENTATION}

\section{1-Functional module division}

According to demand analysis and business logic, the system is divided into 5 functional modules. The functional structure of the system is shown in Figure 2. In addition to basic data management operations such as data addition, deletion, modification, and inspection, each functional module provides comprehensive functions such as data calculation and summary.

(1) Owner information. In the property management, all owner information and resident information need to be registered in detail, and updated and maintained in time. Therefore, the owner information management function needs to be established, which directly determines whether the community property management information system can provide high-quality Property management services, owner information mainly includes name, identity card, sex, telephone, address, community, building, unit, floor, room number, creation time, update time, status, version number, et al.;

(2) Real estate information. Real estate information is the basic content of real estate management. Real estate management personnel need to manage and maintain real estate information in a timely manner. Real estate information management is also one of the most basic functions in community property management. 
Real estate information mainly includes owner information, address, community, area, house type, orientation, structure, type, building, unit, floor, room number, room status, creation time, update time, status, version number, picture path, et al.;

(3) Engineering equipment. In property management, it is necessary to register the information of community engineering equipment in detail, and to update and maintain it in time. Therefore, it is necessary to establish the function of community engineering equipment management, which directly determines the improvement of the maintenance service quality in the community property management. The equipment mainly includes primary key, name, number, type, model, brand, size, power, weight, date of production , service life, status, remarks, creation time, last modification time, data status, version number, et al.;

(4) Personnel management. Personnel management is mainly for community property managers. Property managers are the core of property services. Therefore, it is necessary to manage the basic information and basic data of property managers to ensure the accuracy and change of information Timeliness, personnel management mainly includes primary key, name, sex,position, telephone, identity card ,occupation , resume,age,date of birth, remarks, creation time, modification time, Status, version number, et al.;

(5) Lease management, in order to grasp the rental of items (including housing lease) in the community and ensure the safety of the property in the community, it is required to register and manage the rental of items (including housing lease) in the property management of the community. (Including housing lease) changes in time, the lease management mainly includes primary key, name ofcontract, contract number, type of contract, date of sigaatures, state, first party, party B, appendices,,remarks, creation time, update time, version number, status, et al.

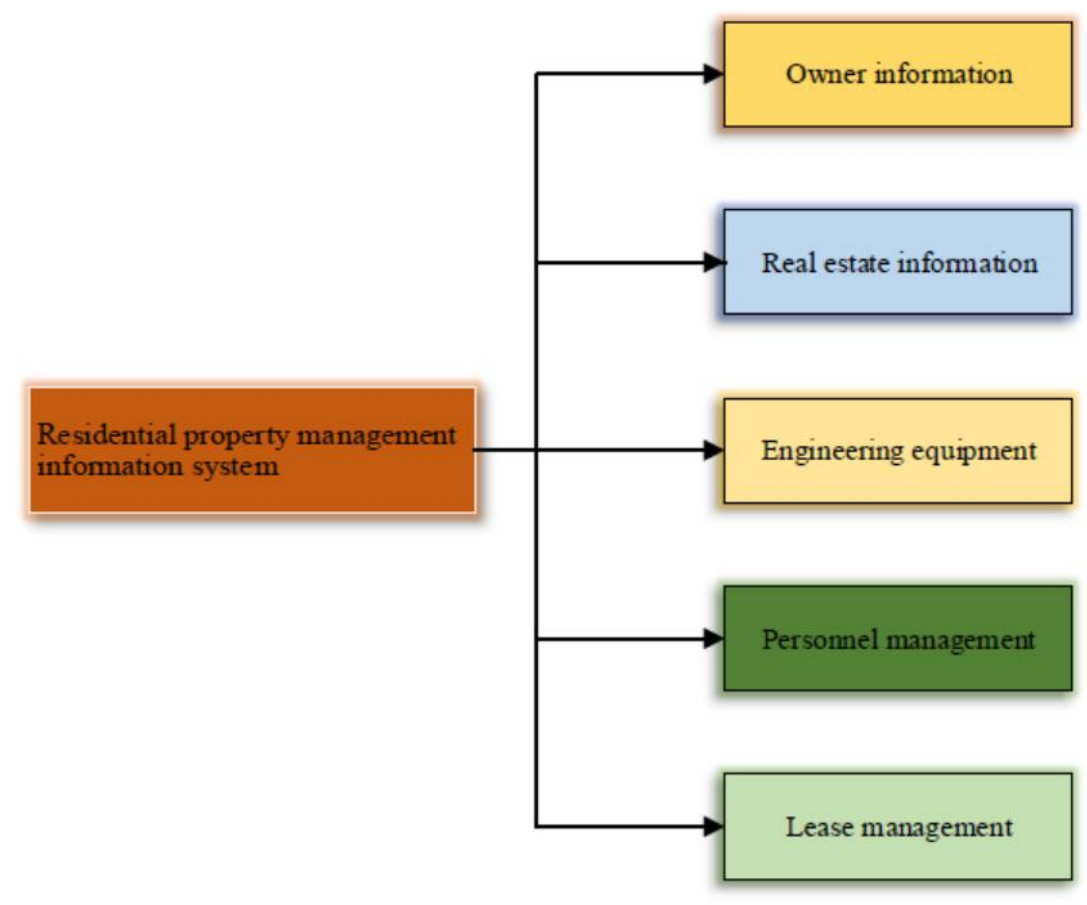

FIGURE 2 System function structure diagram

\section{2-Implementation points}

(1) Selection of development integration framework 
Frameworks such as Spring MVC and Mybatis are integrated and applied in the development environment. These frameworks are optimized and combined according to the layered concept to promote project development, thereby supporting the continuous change of system requirements and continuous expansion of functions, and the low coupling between layers is enhanced Improve the scalability of the system and improve the quality of system development.

(2) System performance design

The system uses MySQL database technology to strictly process the security and data accuracy of related data when developing the system, and fully meets user needs in terms of performance and security; the response time of the system query page is less than 1s, and the response time of new and updated pages Less than 0.3s; the system uses the JAVA development language to complete under the Windows operating system. As long as the system can run normally on a Windows-compatible browser or operating system, it has better adaptability and compatibility, and for those with special needs Users, the system can maintain an interface with other systems in the maintenance phase after completion, and can meet user requirements at any time.

(3) Data input and output design

The system needs to check the validity of data input, which can be printed and output in file format. According to the user's selection of the corresponding function menu, the data is added, deleted, modified, checked and other processing according to the user's operation, and the corresponding information is returned system interface.

(4) Data management capability design

In terms of functional design, the database can be tuned, reorganized, security management, analysis and summary of error reporting, and related data processing, special management of data flow, and independent data management.

(5) User type and authority setting

According to the size of the community and the division of property management functions, the system has set up user types with different functional rights for system administrators, property management managers, property managers, and owners.

\section{4-SYSTEM TEST RESULTS}

After a comprehensive test, the residential property management information system can meet the basic functions. At the same time, it has a good user interface, which is very convenient for users to perform various operations. It can also verify the information entered by the user and provide prompts to the user when the entered information is incorrect. information. System functional test results are shown in Table 1.

TABLE 1 System functional test results

\section{Test items}

User login

Owner information query and editing

Real estate information query and editing

Engineering equipment query and editing

Personnel management query and edit

Rental management query and editing

\section{Test content}

The user enters the correct and incorrect login name and password to verify th The user inquires about the submitted owner information, and realizes the test The user queries the submitted real estate information, and realizes the testing The user queries the submitted engineering equipment, and realizes the testing The user queries the submitted property management personnel, and realizes t The user inquires about the submitted item rental (including housing rental), a

In addition, the residential property management information system was tested for strength, safety, accuracy, response time for querying new and updated pages, flexibility, etc. The test results were all qualified. 


\section{5-SYSTEM APPLICATION AND ANALYSIS}

At present, the system has been in trial operation in 8 different types of communities for one year, and has assisted users in these 8 communities to enter or import some years of historical data. Data for 2020 is continuously being added. The current system is operating stably, and there is no data loss or communication packet loss. In addition, the response time for query, new and update pages has not exceeded the specified time. Because the system has comprehensive functions such as data calculation and summary, the labor intensity of property management personnel is greatly reduced, effectively improving work efficiency by more than $70 \%$.

\section{1-System login}

The system application takes a community as an example. The user enters the community property management information system general interface as shown in Figure 3. Click "Management login entrance" in the upper right corner of the community property management information system interface, and the community property management information system interface diagram appears As shown in Figure 4, enter the correct user name and password in the user name box and password box to log in.

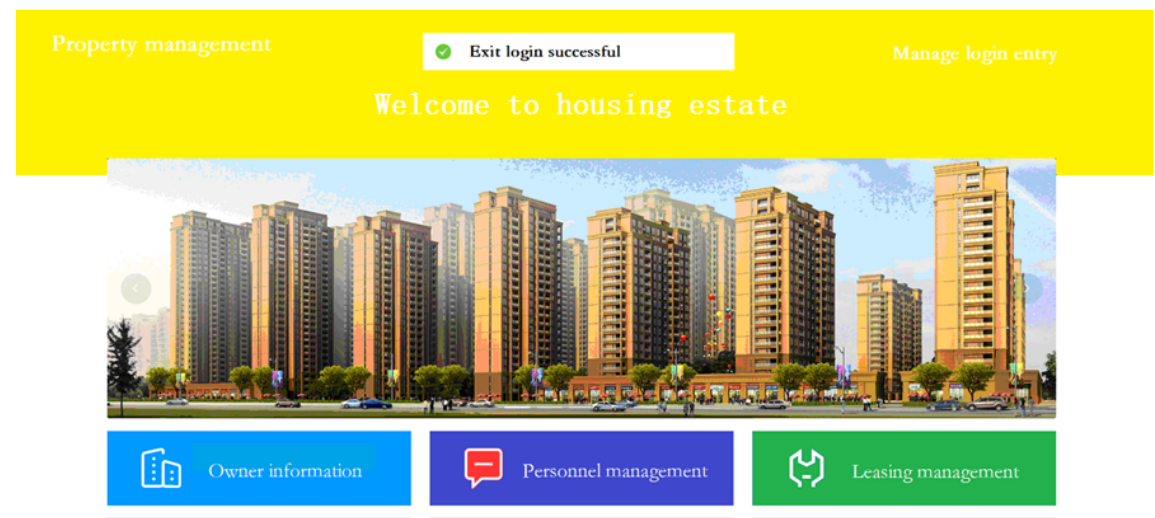

FIGURE 3 General diagram of the residential property management information system

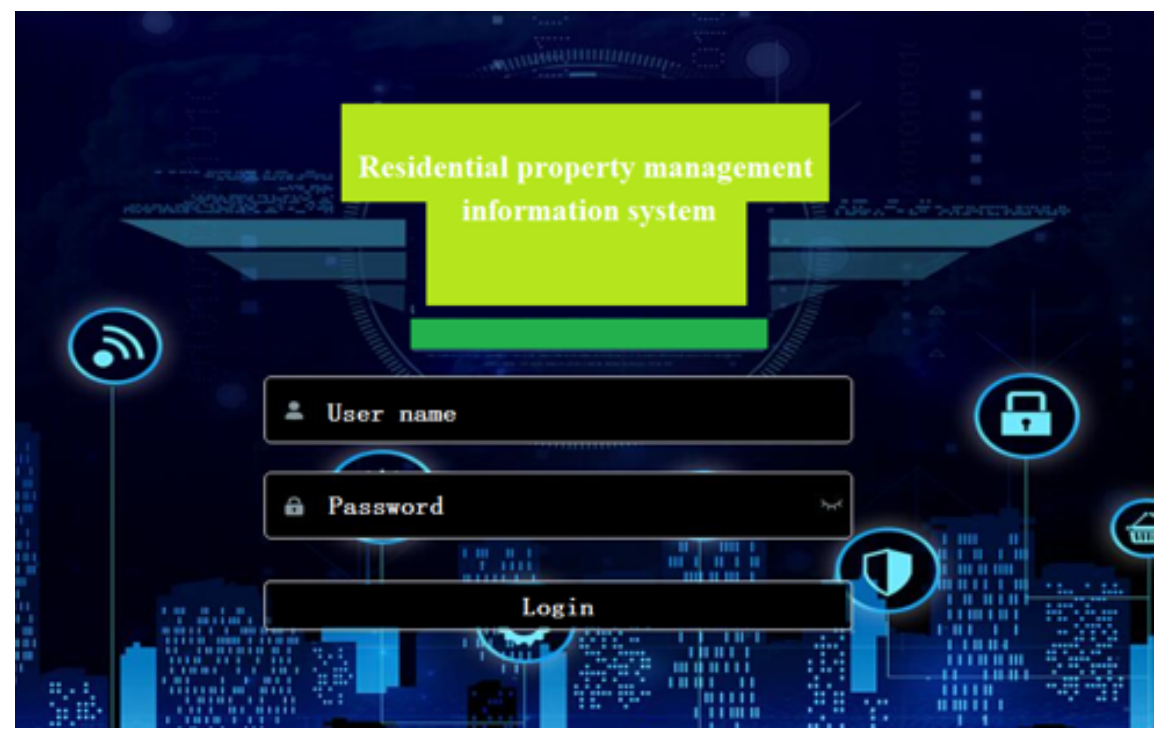


FIGURE 4 Residential property management information system interface

\section{2 - Data reporting}

In the function menu, the owner information, real estate information, engineering equipment, personnel management, lease management and other data are managed in the form of a list, which is edited by the property management manager and property management personnel through the add, delete, modify, and check buttons on the page.

After the property management manager and property management personnel log in according to different functional rights, edit the owner's information, including name, identity card , sex , telephone, address, community, etc.; edit the property information, including owner's information, address, community, area, house type, orientation, structure, etc.; edit Engineering equipment, including primary key, name, number, type, model, brand, size, etc.; edit personnel management, including primary key, name, sex,position, telephone , identity card ,occupation, etc.; edit lease management, including primary key, name ofcontract, contract number, type of contract, date of sigaatures, etc.; the owner user can edit part of the information related to the owner information, real estate management, and lease management function modules according to their authority. The above information is maintained by the system administrator.

System administrators, property management managers, property management personnel, and owner users fill in the reports according to different functional rights. For example, the interface of owner information, real estate information, engineering equipment, personnel management, and lease management in a residential area in September 2019 is shown in Figure 5.
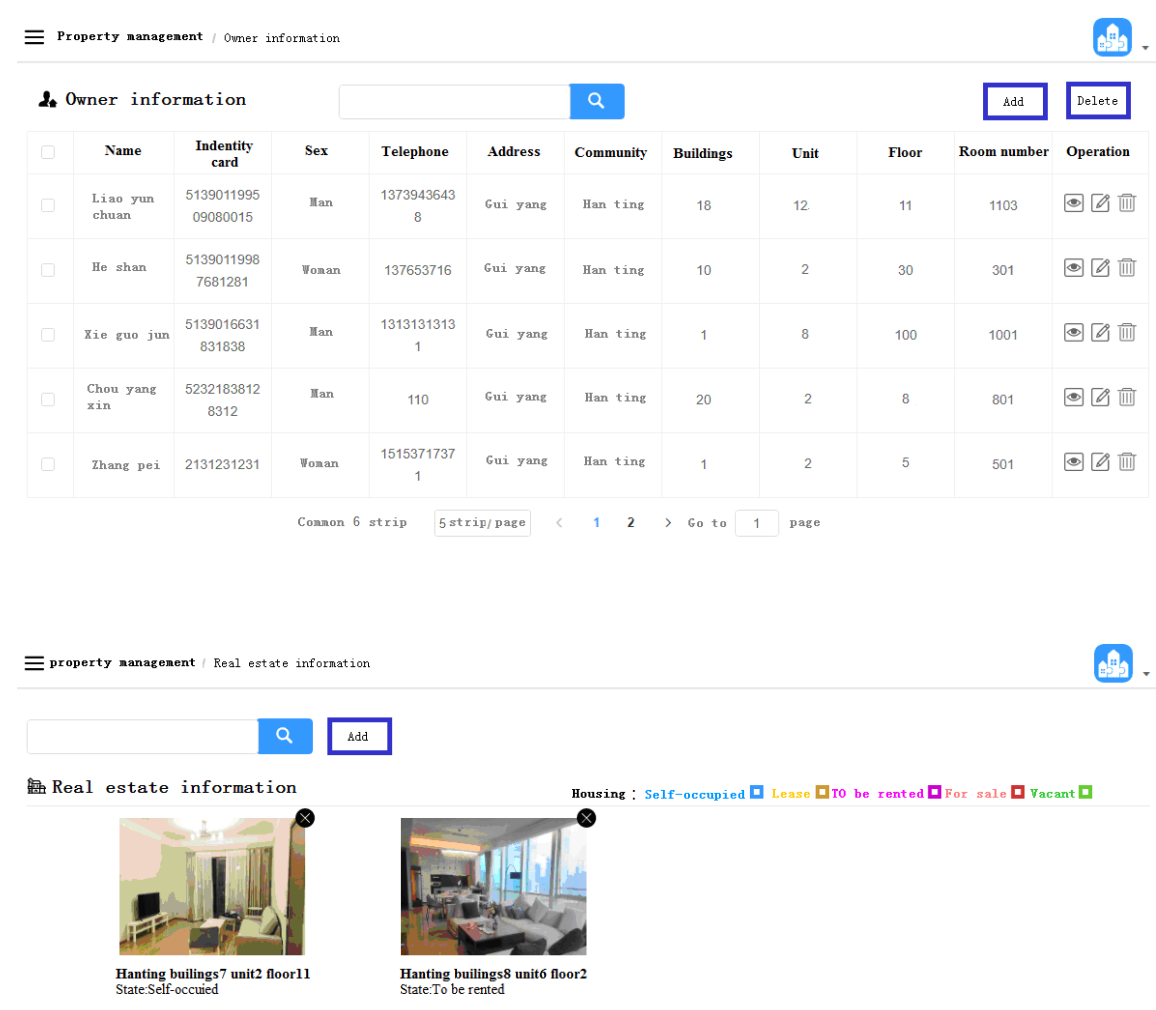

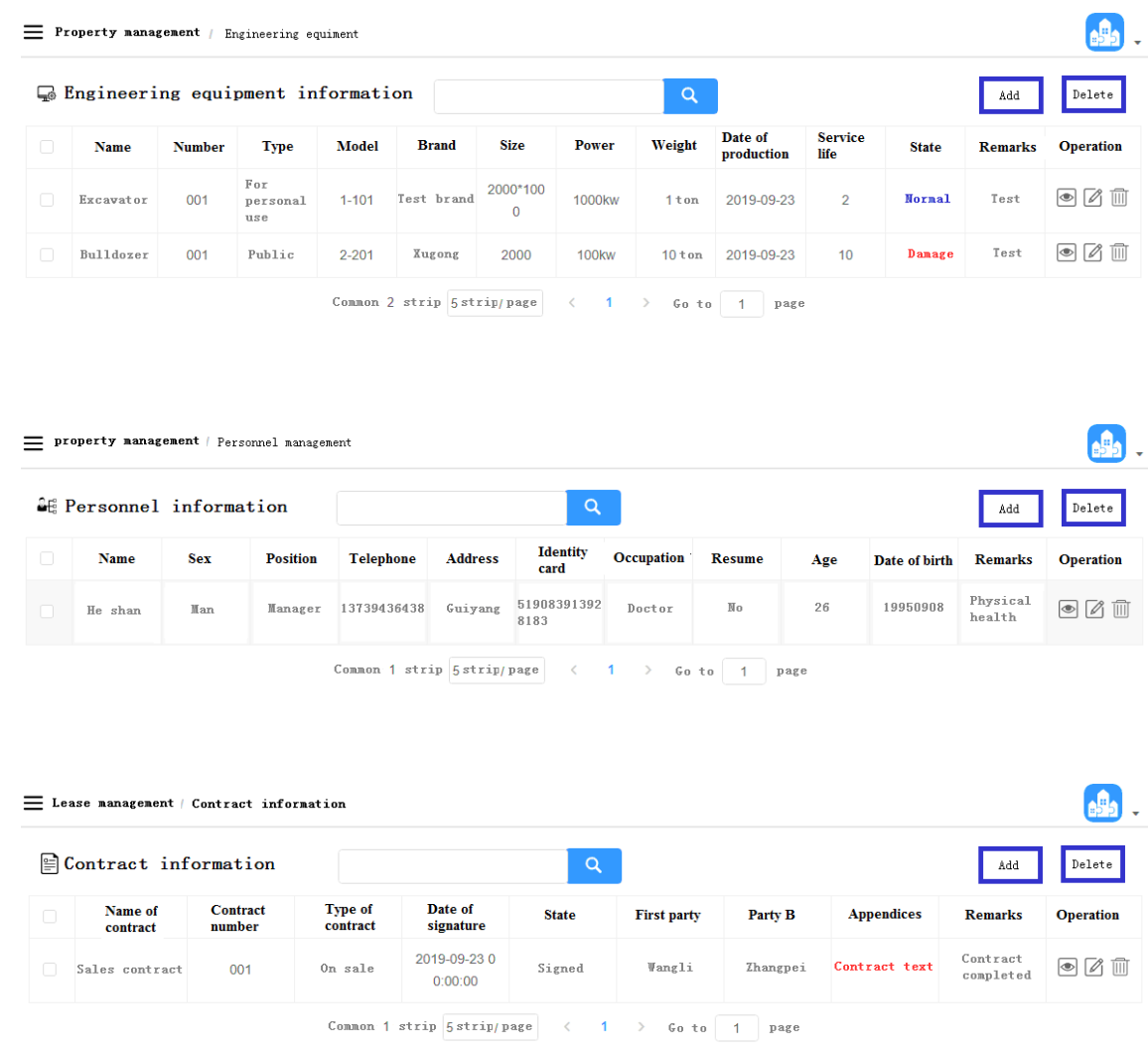

FIGURE 5 Data management interface of a residential area

\section{3 - System application effect}

(1) As the system business design is based on a large amount of demand analysis and data collection, the system can be applied to most communities;

(2) The standardized expression and unified storage of property management data solves the problems of random filling of property management data in the past, which is difficult to accumulate for a long time, difficult to save in the system, and difficult to search and find;

(3) The system has comprehensive functions such as data filtering, calculation, and summary, which greatly reduces the labor intensity of property management personnel and effectively improves work efficiency.

\section{6-CONCLUSION}

The residential property management information system based on the B/S model designed and implemented in this paper combines the needs of property management business to manage various data hierarchically, which better solves the problems existing in the current residential property management informatization. The current system has the following characteristics:

(1) The system adopts the B/S mode, which is simple, convenient, safe and stable to operate. It is not restricted by time and place. Users can access and operate the system where there is Internet and do not need to install special applications on the computer. The system cost is relatively low, the development cycle is short, and the development efficiency is high. At the same time, a responsive design is adopted to support users to access and operate the system through mobile terminals (such as mobile phones and tablets) anytime and anywhere. 
(2) The system business design is based on a sufficient demand analysis, taking into account the characteristics of various types of residential, and constructing a system based on the common characteristics of different types of residential through a large amount of collected data. Restrictions on residential type and property management mode.

(3) The system development integrates three mature frameworks: Spring MVC, Mybatis, and VUE.js, plus the use of layered development concepts, so the system has strong scalability, understandability, testability, and modification, Portability, reusability, easy maintenance, good system compatibility.

(4) The system builds a property management model of "owner + residential ". The management and service objects closely surround the owner and the community. The system has strong comprehensive functions. The labor intensity of the property management personnel is greatly reduced, and the work efficiency is effectively improved by more than $70 \%$. The community owners experience Strong, high satisfaction.

\section{REFERENCES}

1. Zeng xiyin. Design and Implement of Property Management System Based on Internet. Modern Electronics Technique . 2007;30 (8):68-70.

2. Liu ruoyu. Design of Property Management System Based on B/S Mode.Journal of Chizhou Teachers College . 2006;(05):25-27.

3. Wei zongyi. The Design and Implementation of Residential Property Management Based on. NET. Shandong University. 2009:1-23.

4. Sun zhonghua. Research of Intelligent Uptown Facility management system Base On B/S Mode. Dalian Maritime University ; 2014:1-48 .

5. An sibo. The Design and Realization of the Property Management System Based on WEB . Fudan University ; 2010:13-18.

6. Liu chunli, Xu chenglin. The Property Management System of Intelligent Residential Area Design Based on ASP.NET Technology. Computer Knowledge and Technology ; 2008;(27):1966-1967+1972.

7. Yang jun, Zhang huaqiang. Use SSH to Construct the Estate Property Management System. Computer CD Software and Application ;2012;15(20):233-234.

8. Zhong luo, Xu junjie, Peng yu, et al. Design and Implementation of Property Management System Based on Struts and JDO. Computer $\&$ Digital Engineering ; 2016;(03):140-142.

9. Chen hui. Development of Residential Pproperty ManagementSsystem Based on VB. China CIO News ; $2016(04): 53$.

10. Hu Fengjuan. Design and Implementation of Property Management System Based on SSH Architecture. Computer Development \& Applications ; 2014;27(11):40-42+45.

11. Yao fen. Design of Property Management System ASP.NET Architecture.Electronic Design Engineering ; 2015;23(13):40-41+45.

12. Wu ling lin. Residential Property Managem-ent System Based on LINQ.Computer Systemand Applications ; 2013; 22(11):81-85.

13. Alice Christudason. Choice of property management system for residential strata developments in Singapore. Property Management ; 2008;26(2):97 - 111.

14. B.Klingenberg R.J.Brown. Optimization of residential property management. Property Management ; 2006; 24(4):397 - 414 .

15. Wei Yuanyuan,Wang Xue,Wang Rujing, et al. Design and implementation of agricultural production management information system based on WebGIS. Transactions of the chinese Society of Agricultural 
Engineering ; 2018;34 (16):139-147.

CONFLICT OF INTEREST

The author Mingze Ma has no conflict of interest relevant to this article. 